\title{
Investigation the Role of New Technologies in Coping with Natural Disasters
}

\author{
Aleme Keikha $^{1}(1)$, Mohammad Amin Hashemzehi ${ }^{2}$, Abdul Ali Keshtegar ${ }^{3}$
}

Date of submission: 04 Oct. 2019 Date of acceptance: 14 Mar. 2020

\section{Original Article}

\begin{abstract}
INTRODUCTION: The occurrence of natural disasters leads to economic, social, and personal infrastructure damage. Moreover, the government capacities increase rapidly following a direct and major demand for assistance. In these situations, timely communication, information gathering, and coordination to respond to the needs are of critical importance. Therefore, this study aimed to evaluate the effect of new technologies on dealing with natural disasters in Sistan and Baluchistan Province, Iran.

METHODS: This practical study was conducted based on a descriptive-survey method. The population included 100 experts and key members of the Sistan and Baluchistan Crisis Management Coordination Council. In total 80 cases were selected using Cochran's formula and purposive (snowball) sampling method. The data were collected through a 46-item researcher-made questionnaire. The face and content validity of the questionnaire was confirmed by experts, and the reliability of the questionnaire was estimated at 0.94 using Cronbach's alpha coefficient, which indicated acceptable reliability of this scale. The data were analyzed in SPSS software (version 22) through multiple regression to evaluate the research hypotheses.

FINDINGS: According to the results of the Kolmogorov-Smirnov test, the data distribution was normal. Moreover, the results of the multiple regression test showed the effectiveness of new technologies in dealing with natural disasters. Furthermore, operational equipment had the most significant effects on dealing with natural disasters.

CONCLUSION: New information technologies play a significant role in crisis and disaster management. Therefore, they can be beneficial in terms of informing and reducing costs as well as losses during crises and unexpected events.
\end{abstract}

Keywords: Crisis Management; Disaster Management; New Technologies.

How to cite this article: Keikha A, Hashemzehi MH, Keshtegar AA. Investigation the Role of New Technologies in Coping with Natural Disasters. Sci J Rescue Relief 2019; 11(4): 248-59.

\section{Introduction}

$\mathrm{D}$ isasters and environmental hazards have long been considered the most destructive factors of harm to humans, society, and the environment. The results of the studies reveal that crises do not determine the extent of damage, and it is the officials' reactions to the crisis that leads to its identification. Although the level of preparedness on various types of natural disasters is regarded as one of the important indicators of the development of countries, less attention is paid to emergencies and crises in the development programs of most countries across the world (1). The force of nature can be millions of times more powerful than the available bombs and explosives (2). History has witnessed uncontrollable and unpredictable forces of nature, such as earthquakes, volcanic eruptions, droughts, floods, heat shocks, tornadoes, as well as tropical and marine storms. Moreover, they endangered the

1-PhD, Department of Management, University of Sistan and Baluchestan, Zahedan, Iran

2-MSc, Executive Management, Red Crescent Society, Sistan and Baluchistan Province, Zahedan, Iran

3-PhD, Department of Management, University of Sistan and Baluchestan, Zahedan, Iran

Correspondence to: Aleme Keikha, Email: Aleme.keikha@entp.usb.ac.ir 
foundation of human life since its inception (3). Considering that such natural processes have negative effects on human life, some experts have called them disasters. According to Marto et al. (2018), "natural disasters" are events that cause extensive human, economic, and natural losses with power more than that of humans (4). Moreover, Tokakis et al. (2019) indicated that "natural disasters" are a natural or manmade phenomenon that is generally occurred in a particular place or time and can endanger all or part of a society (5). In the same line, Pennington et al. (2018) believe that "natural disasters" are natural phenomena leading to the instability of the socio-economic system and a serious imbalance between the supply and demand in social resources (6). Iran is the sixth most disaster-prone country in the world. Out of all cities in this country, only $3 \%$ of them are located in low-risk areas. Furthermore, Iran has experienced 30 events out of 43 possible unexpected natural disasters worldwide, the most common of which include earthquakes, floods, droughts, crop pests and animal diseases, as well as wild land fires (7).

Moreover, Iran accounts for $6 \%$ of the world's natural disaster casualties; however, it is home to only $1 \%$ of the world's population. With this background in mind, this question could be raised whether there is a possibility to take action to prevent or reduce the risks from natural hazards (8). According to Traore et al. (2018), there is a severe disruption in the activities of society during a crisis. Therefore, people, properties, and the environment are severely damaged, and society can merely benefit from its available resources (9). Accordingly, crisis management should be initiated with a thorough audit of hazards and the identification of risks that can lead to significant and fundamental problems (10). Similarly, Dave (2015) indicates that crisis management is essential to prevent a crisis or minimize its effects. Therefore, the worst situations should always be taken into account accompanied by explanations to manage and resolve them (11).

According to the literature, the crisis does not determine the level of damage; however, officials' reactions lead to its identification. Poor crisis management planning constantly increases the extent and amount of damage. This is why crisis management planning has obtained significant importance so far (12-14). Nowadays, it is of utmost importance to make use of the bitter experiences of the past, an unknown future, and lurking hazards to prevent the occurrence of unexpected events. Moreover, in the event of natural disasters, we must step towards new crisis management planning to minimize the casualties (12). According to Reddy et al. (2009), information and communication management is one of the critical issues in responding to emergencies in natural disasters since effective and timely response in the emergency requires moment-by-moment and timely analysis of the situation and information to assess the needs and available resources that may change unexpectedly (15).

Pérez et al. (2012) also believe that natural disasters cause serious damage to economic, social, and personal infrastructures, and following a direct and large demand for assistance, the government has no longer the capacity to fulfill the needs. In such situations, it is critical to regard timely communication, information gathering, and rigorous coordination to respond to the needs (16).

Therefore, the increasing growth of facilities and human resources leads us to make use of new management techniques to manage crises and maintain human and social capital. In addition, recent advancements in technology and new areas of information technology have caused a significant change in the provision of services and the level of management planning in various fields of crisis management. Lack of timely information and up-to-date equipment and facilities have resulted in the inefficiency of crisis management when dealing with crises. Accordingly, the provision of new solutions based on up-to-date and efficient technologies seems to be more efficiently and rapidly, compared to the traditional and conventional ones (17). It should be noted that the preparation of rescue, treatment, and support teams is required in case of unexpected disasters; otherwise, it leads to increasing numbers of casualties, injuries, and damages. Obviously, "new information and communication technology" can help us in all three areas (12).

Wojciechowicz et al. (2012) demonstrated that the rescue teams can utilize new information technology to find the injured people and reduce the time of rescue and relief process. Moreover, regarding the treatment and care domain, new 
information technology helps the patients be referred to health care centers based on available capacities, reduce the treatment costs, and increase the speed of providing care and information. Considering the support domain, this technology is effective in the delivery of equipment to the affected areas based on real needs and sufficient information (18).

In this regard, it is of critical importance that organizations, such as the Red Crescent Society, which is involved in the operations and plays a remarkable role in this area make use of new communication and information technologies in crisis management. Due to the current infrastructures and the risks, Sistan and Baluchistan Province, Iran, is more prone to damages, compared to other provinces. Therefore, this province must pay more attention to the components of the new technologies mentioned in this study.

Data collection from the inflicted areas using mobile technology is more rapid and reliable. Nowadays, new generations of technologies and mobile communications are created and marketed with many different capabilities. Moreover, the rapid and progressive growth of new technologies paves the way for a promising future in terms of employing technologies before, during, and after disasters as well as crises.

These technologies are widely used in disaster risk reduction programs; however, they are less experienced in the field of disaster response and management. Therefore, crisis management requires a variety of facilities and conditions the same as other management systems. In addition, information systems and up-to-date equipment and facilities (new technologies) play a more critical role in this type of management, compared to other parameters.

The utilization of new technologies to overcome natural disasters and reduce the losses and casualties is critical in Sistan and Baluchistan Province, Iran, due to its geographical location, area, infrastructure, population distribution, and existing hazards. Therefore, this study aimed to investigate the role of new technologies in dealing with natural disasters.

\section{Review of the Literature}

The results of a statistical analysis conducted by Chung (2016) in 1990-2016 showed an increasing trend in the occurrence of natural disasters. According to statistics, the severity of disasters, the number of casualties, the number of injured people, and the number of financial losses were 4, 7, 5, and 38 times higher than before, respectively (19).

Iran is also one of the most disaster-prone countries in the world. Every 25 minutes, one person dies in an accident in Iran. Moreover, hundreds of people are killed in urban and road accidents every day, and the same number of people drown in Iran waters every year. Moreover, we do regularly hear of the death of the mountaineers and climbers. Additionally, since Iran is located on the fault lines, destructive earthquakes often occur in this country. It is worth mentioning that every year, many villages and cities in Iran are affected by the flooding.

In general, regarding the geography of Iran, the occurrence of natural disasters is an integral part of people's lives. On the one hand, the geographic and climatic diversities in Iran have increased the probability of occurrence of some natural disasters in the country. On the other hand, the majority of unexpected events, such as floods, wildland fire, drying lakes and wetlands, landslides, development of deserts, an increase in the fine dust, blowing sands, air pollution, and the reduction of drinking water and agricultural resources are all associated with the destruction of the environment and the loss of ecological resources. In other words, humans have effects on the occurrence of all natural disasters, except for earthquakes (20).

Therefore, natural disaster management is a very important management issue in the country. Moreover, it is important to note that, immediately after the occurrence of natural disasters and crises, significant changes are made, which put a heavy burden on the shoulders of the crisis managers. This is due to the lack of information about what happened, cause, number of injured and victims, extent of the destruction, and what needs to be done to deal with the problems. Therefore, decisions are difficult to make, and misconceptions and rumors spread among the affected people (21).

Considering this issue, the core of all actions to reduce and control natural disasters is the utilization of complete and integrated information. One of the basic management components of casualties induced by natural disasters is the existence of accurate and sufficient information 
that has effects on the quality of care and cost control. This process requires that data collection, processing, and distribution be the basis for further research and understanding of unexpected events, thereby improving care and health and increasing help.

Due to a lack of a comprehensive system based on new technologies in Iran, crisis management is not implemented systematically, and the existing data include different formats. Therefore, the information is not provided quickly. Reviews and analyses on natural disasters in Iran and the performance of relief workers indicate major limitations and inadequacies in terms of information management, finding locations, and disaster assessment from a crisis management perspective. Regarding information management and technology, Iran stands far from global standards. Therefore, it is necessary to investigate the role of new technology and its implementation in natural disaster crisis management. Bourletidi (2013) indicates that lack of proper use of information and effective communication between decision makers and executives in large and small sections is one of the most effective causes of failure crisis management and damage reduction (22).

Christos (2015) believes that different information systems are employed in crises. However, each system uses a separate database, and none of these information systems are interconnected. Therefore, it is obvious that communication information systems play a remarkable role in establishing proper communication, participation, coordination, and integration, which are all essential components in crisis (23). Therefore, in crisis management, proper communication, participation, coordination, and integration of all elements that play a role in the crisis outcome is the most important factor that ensures the success of the operational plan components (22).

The role of information technology in the crisis management planning process is:

1. Integration of all organizations and institutions that play a role in the implementation of crisis management.

2. Data gathering, organizing, and analyzing the complete records of previous crises; analyzing and evaluating the crises and experiences; evaluating the possible risks and methods of overcoming; and investigating the situations.
Moreover, the Anti-Crisis Headquarters should save the information in integrated databases and networks. In case of crises that are likely to occur, the Anti-Crisis Headquarters is required to identify, evaluate, and analyze all the early signs and symptoms of crises using GIS, GPS, ES, and OIS.

3. Developing and formulating comprehensive crisis management policies, strategies, programs, and plans.

4. Organizing and distributing human and financial resources.

Information technology can also play a major role in the process of crisis management and returning to normal situations, which includes:

1. Operation control and monitoring: with the utilization of information and communication technology and remote thinking systems, it is possible to manage and control crises from anywhere and make new decisions at any time.

2. Prevention of legal abuses: legal abuses can be prevented by the utilization of information and communication technology, administrative documents, and geographic information systems.

3. Rescue and relief: with the utilization of advanced information and communication technology, such as TPSs, all crisis support information can be stored and analyzed. Furthermore, they can be used as guidelines to guide the rescue and relief teams (14).

There is an upward trend toward the use of new technologies, including communication, digital, nano, and biologic technologies, at all stages of the crisis, including dealing with events and disasters. Among the application of new technologies in the coping phase and reconstruction, one can name the provision of remote services; utilization of audio-visual media to provide psychological, social, and supportive assistance; use of databases, decision-making databases, as well as rehabilitation and biosystems. The reviews on the available studies revealed that the application of new technologies in dealing with events and disasters can be summarized as follows:

\section{Management Information Systems (MIS)}

Management information systems are applied information systems providing the organization and management with information to make decisions, plan, organize, control and monitor, coordinate communications, and lead the 
organization (24). Therefore, one of the main reasons for the inefficiency and failure of crisis management is the poor or wrong decisions that are made due to a lack of sufficient and appropriate information. This can be the result of paying no attention to the importance of information; lack of proper infrastructure; as well as poor performance in production, organizing, storing, and disseminating appropriate, accurate, reliable, timely, and complete information before and during a crisis (25).

\section{Geographic Information Systems (GIS)}

The geographic information system is a new database including a set of visual information (maps) as well as descriptive and digital information related to land features. There is a significant relationship between these two groups of information that is regarded as a simple model of reality (26). Today, GIS is of special importance in crisis management. With the help of a database designed in the GIS environment, it is possible to provide information layers (i.e., the exact location of the urban population settlements; communication routes; water, electricity, and telecommunications lines; streams and water networks; springs, aqueducts, and wells; fire stations; relief centers; and police stations) to identify the endangered zones in order to predict the hazards and get prepared for any unfortunate incidents (12).

\section{Decision support system}

This system is designed by the combination of simultaneous data monitoring and transmission, dynamic damage estimation models, and Web technology. The results of this system are sent as a warning message to the decision-making center and help the decision-maker prepare for and respond to the crisis (13). Timmermans (2007) also states that the essence of crisis management is to make an appropriate decision, and crisis management is usually synonymous with decision making (27). The decision support system is one of the new approaches to dealing with natural crises. According to Holbic et al. (2011), the importance of making decisions based on reasoning and logic along with the increasing development of new technologies has led to the use of computers as effective tools to support decision-making process (28).

\section{Telemedicine}

Greenwald et al. (2018) believe that telemedicine uses information and communication technology to provide health care services to people who are far away from health care providers (29). Telemedicine is a bridge between medical sciences and engineering, in which medical targets benefit from engineering facilities to improve the community health (30).

\section{Global location system (GPS)}

This global system, which has been utilized across the world for years for geographical locations, altitude, and location, can be considered a model assisting relief workers and crisis managers. This system, which is automatically installed in most of the cell phones and vehicles, is a tool for relief and assistance that can be used by all people (31).

\section{Space Science (satellites)}

Space science can be considered a set of sciences about space and its environment, as well as technologies, and space industry. The space technologies play a significant role in the entire crisis management cycle before the occurrence of disaster for preparedness and after the disaster in order to assess the damage. Out of space science applications in crisis management, one can name the design and construction of satellites and supply of operational remote sensing satellites (32).

\section{Operational equipment}

The type and quality of equipment used by operational teams in different parts of rescue operations correlated significantly with the effectiveness of team performance. In other words, the utilization of modern equipment leads to successful performance in terms of reducing the number of casualties in the disaster response phase (33).

\section{Nanotechnology}

Nanotechnology can be used in the production of medical equipment, clothing, specialized equipment, rescue and relief operations, building materials, sensors, and smart polymers. Regarding crisis management, this technology is beneficial in earthquake control, fire, and water purification (nanofiltration) (34).

\section{Biotechnology}

Science is the use of microorganisms in favor 
of human beings. Today, biotechnology is considered among the seven key sciences in the world. One of its main applications is the production of operational supplies and consumable equipment and materials that are highly compatible with the environment. In this technology, microorganisms or plants are used to eliminate toxic and stable wastes or convert them into other useful substances (34). Biotechnology has recently attracted a great deal of attention in the field of the water crisis and air pollution prevention.

The studies conducted by Estelaji and Yari (2017); Rahimi and Afsharipour (2016); Shahrokh (2016); Bayat Sarmadi Baharan et al. (2016); Motaghed et al. (2015); Faraji Sabkobar, Hassan Ali et al. (2015); Eghbali et al. (2014); Taghizadeh et al. (2013); and Riahi (2005) investigated different dimensions of technologies in critical situations. Moreover, various dimensions of technology during the crisis and natural disasters were evaluated in the studies performed by Gambor and Rocky (2018) Songwathana (2018); Sovacool et al. (2018); Herath (2017); Cassar et al. (2017); Kapucu and Haupt; as well as Latifi and Tayli (2014). They acknowledged that these technologies if used properly would play an effective role in reducing natural disasters.

\section{Methods}

This practical study was conducted based on descriptive survey design. The population of the present study included 100 experts and key members of Sistan and Baluchestan Crisis Management Coordination Council, including the heads of specialized crisis management committees, civil engineering deputies and provincial governors, experts in Zahedan University of Medical Sciences, experts in electricity, water and waste water companies of the province, experts in the general departments of roads and urban development, road maintenance and transportation organization, experts in the Red Crescent society of the province, the heads of the municipalities of the province, and experts in the management and planning organization of the province. The sample size was determined at 80 cases using the Morgan table and purposive (snowball) sampling method.

The data were collected using libraries (textbooks, scientific journals and published articles, dissertations, and Internet scientific resources) and a field survey (researcher-made questionnaire). This 46-item questionnaire was developed based on the meta-synthesis method to identify new technologies with ordinal scales that are scored based on the Likert scale. This tool consists of two sections to seek information about the demographic characteristics of the participants (section one) and ask questions about the new technologies and their role in dealing with natural disasters (Table 1).

It should be noted that the face and content validity of the questionnaire was confirmed by experts, and reliability of the questionnaire was determined at 0.94 using Cronbach's alpha indicating the high validity of this tool. Moreover, there was a significant correlation among the questions. In other words, it can be claimed that the results of this test correspond to those if it will repeat for the same construct under the same condition. The data were analyzed in SPSS software (version 22) through multiple regression.

\section{Findings}

Table 2 summarizes central tendency indices and the variable distribution.

Table 1. Variables, factors, and scoring type in the questionnaire

\begin{tabular}{|c|c|c|}
\hline Variables & Question numbers & Scoring system \\
\hline Management information systems & $1-3$ & Likert \\
\hline Geographic information systems & $4-9$ & Likert \\
\hline Decision support system & $10-12$ & Likert \\
\hline Telemedicine & $13-14$ & Likert \\
\hline Global location system & $15-19$ & Likert \\
\hline Space Science & $20-26$ & Likert \\
\hline Operational equipment & $27-29$ & Likert \\
\hline Nanotechnology & $30-33$ & Likert \\
\hline Biotechnology & $34-36$ & Likert \\
\hline Dealing with natural disasters and events & $37-46$ & Likert \\
\hline
\end{tabular}


As can be seen in Table 2, regarding the central tendency indices and the independent variable distribution (new technology) in management crisis, decision support systems and global location system obtained the highest (3.42) and lowest (2.83) mean scores, respectively. Moreover, dealing with natural disasters and events had an average score of 3.3.

\section{Normal distribution of the variables}

Kolmogorov-Smirnov test was used to evaluate the normality of data distribution (Table 3).

The results of the Kolmogorov-Smirnov test on the independent variable (i.e., new technologies in crisis management and its components) and the dependent variable (i.e., dealing with natural disasters) with calculated statistics and a significance level greater than (0.05) showed that the variables had a normal distribution. Moreover, assuming that the variables are on an interval scale, parametric statistics can be used to analyze the research hypothesis.

\section{Evaluation of the Research Hypothesis}

Multiple regression was used to evaluate the research hypothesis: "the use of new technologies has a significant effect on dealing with natural disasters in Sistan and Baluchistan province" (Tables 4 and 5).

According to the results of multiple linear regression analysis (simultaneous model) and the findings in Table 4, the multiple correlation coefficient was obtained at $\mathrm{r}=0.736$, which indicates the relationship of new technologies and its components with dealing with natural disasters. Since the adjusted coefficient of determination ( $\mathrm{R} 2 \mathrm{adj}$ ) is equal to 0.648 , all predictor variables included in this model explain $64 \%$ of the variance of the variable response to natural disasters. Considering that the level of significance in the test $(0.000)$ is less than 0.01 , the $\mathrm{HO}$ is rejected; accordingly, the linear regression model is significant at the level of 0.01 .

As can be seen in Table 4, the adjusted coefficient of determination is estimated at 0.64 , which indicates that $64 \%$ of the changes in the dependent variable (dealing with natural disasters) can be expressed by the independent variable (new technologies) in the regression model. Moreover, the calculated f-statistic was determined at 92.21, and the level of significance was estimated at 0.000 , which was less than 0.05 . Therefore, the regression model is significant with

Table 2. Central tendency indices and the variable distribution

\begin{tabular}{ccccc} 
Variables & Mean & Median & Standard deviation & Variance \\
Management information systems & 3.23 & 3 & 0.61 & 0.377 \\
Geographic information systems & 3.23 & 3 & 0.54 & 0.29 \\
Decision support system & 3.42 & 3 & 0.61 & 0.37 \\
Telemedicine & 3.41 & 4 & 0.63 & 0.4 \\
Global location system & 2.83 & 3 & 0.66 & 0.44 \\
Space Science (satellites) & 3.12 & 3 & 0.47 & 0.22 \\
Operational equipment & 2.9 & 3 & 0.56 & 0.32 \\
Nanotechnology & 3.31 & 3 & 0.63 & 0.39 \\
Biotechnology & 3.37 & 3 & 0.66 & 0.44 \\
Dealing with natural disasters and events & 3.3 & 3 & 0.54 & 0.297 \\
\hline
\end{tabular}

Table 3. Kolmogorov-Simonov test results

\begin{tabular}{|c|c|c|c|}
\hline Variables & Statistics & $\begin{array}{l}\text { mogorov-Smirnov test } \\
\text { Level of Significance }\end{array}$ & Status \\
\hline Management information systems & 0.094 & 0.078 & Normal \\
\hline Geographic information systems & 0.175 & 0.059 & Normal \\
\hline Decision support system & 0.233 & 0.051 & Normal \\
\hline Telemedicine & 0.195 & 0.54 & Normal \\
\hline Global location system & 0.12 & 0.067 & Normal \\
\hline Space Science (satellites) & 0.105 & 0.069 & Normal \\
\hline Operational equipment & 0.098 & 0.55 & Normal \\
\hline Nanotechnology & 0.116 & 0.061 & Normal \\
\hline Biotechnology & 0.163 & 0.059 & Normal \\
\hline Dealing with natural disasters and events & 0.092 & 0.088 & Normal \\
\hline
\end{tabular}


Table 4. Multiple correlation coefficient results

\begin{tabular}{c|cccc} 
Sig & F & Balanced R2 & R2 & R \\
\hline 0.000 & 92.214 & 0.648 & 0.871 & 0.736 \\
\hline
\end{tabular}

Predictor variables: new technology and its components

Criterion variable: dealing with natural disasters

Table 5. Multivariate regression results and regression equation process

\begin{tabular}{cccccc}
\hline Predictor variable & $\begin{array}{c}\text { Criterion } \\
\text { variable }\end{array}$ & $\begin{array}{c}\text { Beta } \\
\text { coefficient }\end{array}$ & $\begin{array}{c}\text { B } \\
\text { coefficient }\end{array}$ & $\begin{array}{c}\text { T-value } \\
\text { Sig }\end{array}$ \\
Management information systems & & - & 0.511 & 2.997 & 0.003 \\
Geographic information systems & & 0.168 & 0.177 & 2.622 & 0.010 \\
Decision support system & & 0.123 & 0.123 & 1.963 & 0.008 \\
Telemedicine & Dealing with & 0.449 & 0.349 & 2.005 & 0.002 \\
Global location system & natural disasters & 0.252 & 0.232 & 3.552 & 0.001 \\
Space Science (satellites) & and events & 0.361 & 0.291 & 11.278 & 0.020 \\
Operational equipment & & 0.331 & 0.368 & 5.978 & 0.020 \\
Nanotechnology & & 0.541 & 0.408 & 3.303 & 0.050 \\
Biotechnology & & 0.236 & 0.229 & 1.914 & 0.000 \\
Dealing with natural disasters and events & & 0.101 & 0.117 & 1.301 & 0.000 \\
\hline
\end{tabular}

95\% confidence. According to Table 5, the standardized and non-standardized coefficients indicate the impact and predictability of utilizing new technologies on dealing with natural disasters during a crisis. Furthermore, the results of the standard beta coefficient $(\beta)$ can be used to evaluate the relative importance of the variables.

Therefore, regarding the comparison of new technology components (management information systems [0.168], geographic information systems [0.123], decision support systems [0.449], telemedicine systems [0.252], global location systems [0.361], space science (satellites) [0.331], operational equipment [0.541], nanotechnology [0.236], and biotechnology [0.101]), it can be seen that operational equipment (0.541) and decision support systems (0.449) are more significant in predicting changes in dealing with natural disasters, compared to other variables.

Furthermore, since all coefficients are positive, a standard deviation of change in each of the components considering the calculated coefficients results in a change and improvement in the dependent variable (i.e., dealing with natural disasters).

Following is the regression equation of dealing with natural disasters considering the predictor variables based on the data in Table 5 .

$$
\begin{gathered}
Y=a+b_{1} X_{1}+b_{2} X_{2}+b_{3} X_{3}+b_{4} X_{4}+b_{5} X_{5}+b_{6} X_{6}+b_{7} X_{7}+b_{8} X_{8}+ \\
b_{9} X_{9}
\end{gathered}
$$

$$
\begin{gathered}
\mathrm{Y}=0.511+0.177(\mathrm{X} 1)+0.123 \\
(\mathrm{X} 2)+0.349(\mathrm{X} 3)+0.232(\mathrm{X} 4)+0.291(\mathrm{X} 5)+0.368(\mathrm{X} 6)+0 . \\
408(\mathrm{X} 7)+0.229(\mathrm{X} 8)+0.117(\mathrm{X} 9)
\end{gathered}
$$

In the above model, the symbols signify the following inforamtion:

Y- Dealing with natural disasters and events

(X1)- Management information systems

(X2)- Geographic information systems

(X3)- Decision support system

(X4)- Telemedicine

(X5)- Global location system

(X6)- Space Science (satellites)

(X7)- Operational equipment

(X8)- Nanotechnology

(X9)- Biotechnology

With respect to this equation, the amount of dealing with natural disaster variable will change due to alterations in the independent variable (i.e., new technology and its components). In other words, the components of new technologies play a partial role in the identification of dealing with natural disaster variable. Based on the above relationship, for each change of one unit in management information systems, GIS, decision support systems, telemedicine systems, global location systems, space science, operational equipment, nanotechnology, and biotechnology, the average changes in the mean of dealing with natural disasters are about $0.168,0.123,0.449$, 


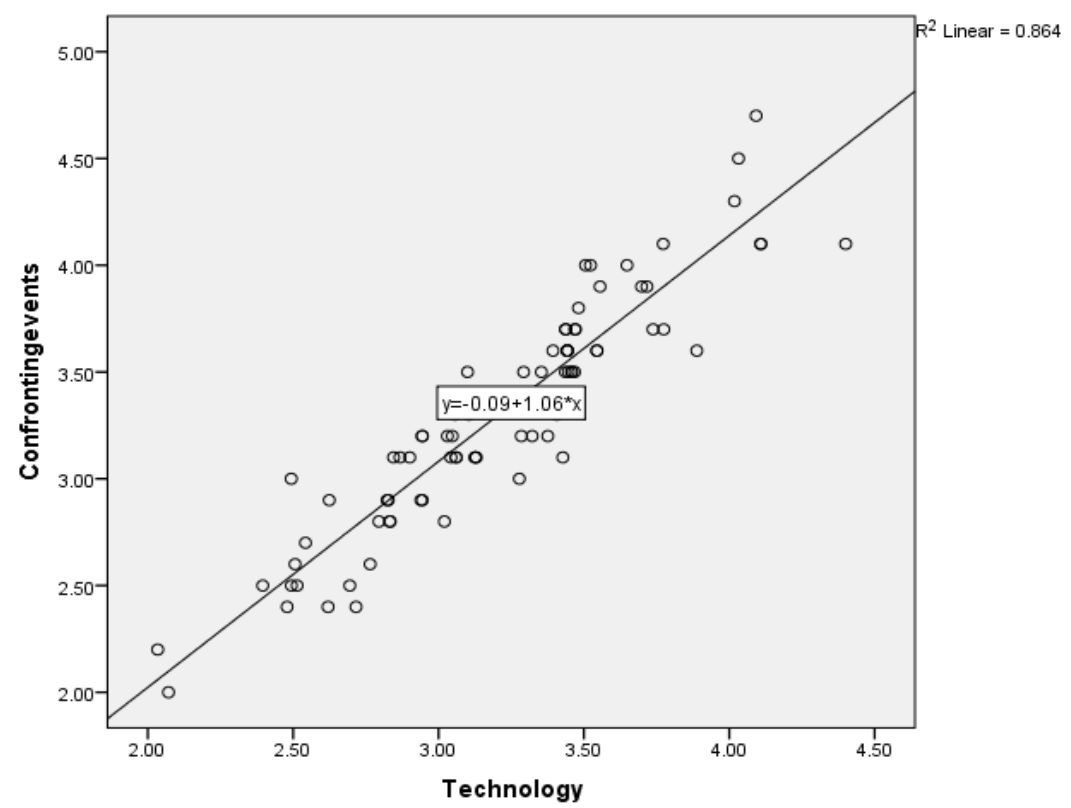

Diagram 1. Distribution with the regression line of the hypothesis

$0.252,0.361,0.331,0.541,0.236$, and 0.101 units, respectively.

As can be seen in the diagram, the slope of the regression line is 1.06 , which indicates the positive effect of new technologies on dealing with natural disasters. Moreover, the $\mathrm{R}^{2}$ value reveals that about $87 \%$ of the changes in the dependent variable (i.e., dealing with natural disasters) can be explained by the new technology variable.

\section{Discussion and Conclusion}

This study aimed to evaluate the role of new technologies in dealing with natural disasters in Sistan and Baluchistan Province, Iran. According to the regression equation, the beta coefficient of the new technologies is significant at the error level of less than 0.05. Therefore, they are effective in dealing with natural disasters. Moreover, since the beta coefficient is obtained at 1.058 , and it is found that with one unit increase in the use of new technologies during the crisis, prevention and dealing with disasters improves by 1.058 units. According to the results, the research hypothesis was confirmed in this study indicating the effect of new technologies on dealing with natural disasters. This result is consistent with the findings of a study conducted by Faraji Sabkolbar and Hassan Ali et al. (2015). They showed that the utilization of technologies, such as cell phones can be an effective factor in crisis management since they are simple to use and learn, as well as cost-effective.

Eghbali Andisheh et al. (2014) also noted the role of new technologies in the effectiveness of crisis management. Similarly, Taghizadeh et al. (2013) revealed that new technologies, including communication technologies, as well as digital and nanotechnologies are effective in all stages of the crisis, including disaster rehabilitation. In a study conducted by Gambor and Rocky (2018), it was shown that new technologies could affect optimal crisis management by reducing response time, improving group coordination, providing proper information to stakeholders, making relationships between different organizations and their stakeholders, and standardizing communication.

The results of a study conducted by Kapoku and Hoppet (2017) reveal that information communication technology is a vital tool to support effective communication and decisionmaking in complex and unknown environments arising from natural disasters. The advances in new technologies accompanied by their continuous effect have modified information sharing and decision-making during natural disaster crises, thereby influencing every stage of the crisis management process.

In a similar way, Mehrabi (2014) in a study emphasized the need to use communication and information technology, especially in crisis management, which is consistent with the result 
of this study. The findings of this study reveal the effectiveness of new technologies on the improvement of crisis management performance. Furthermore, information technology plays a significant role in dealing with environmental crises and natural disasters.

The utilization of different systems based on information technology can affect the coordination and integration of all organizations and institutions that are involved in dealing with the crisis. The systems, such as management systems, GIS, decision support systems, telemedicine systems, and global location systems should collect, organize, and analyze the information about the complete history of previous crises, crisis analysis and evaluation, gained experiences, reviews and possible risks, and possible prevention methods. Moreover, Anti-Crisis Headquarters are obliged to compile and save this information in integrated databases and networks.

Furthermore, satellite data can be beneficial in determining the location, the spread and progression of the crisis, and identification of safe and high-risk areas. In the same line, equipment, such as robots can play a remarkable role in rescue and relief. Therefore, it is predictable that the use of systems, science, and equipment based on new technologies can have effects on dealing with natural disasters and crises.

Given the confirmed effect of new technologies on dealing with disasters, the following suggestions should be taken into account:

The managers are suggested to pay special attention to the application of technologies, especially communication and information technology in crisis management. In this regard, they have to review the existing information systems, investigate novel methods of using information, and establish new systems, such as management information systems, decision support systems, communication systems, as well as geographic information and location. Moreover, it is of utmost importance to utilize space science in cooperation with the Iranian Space Agency, and make an agreement with this organization to benefit from the experts in this agency. In addition, the use of relief equipment, such as robots designed by students and academic elites (first piloted in maneuvers) can be taken into account while planning management crisis programs.

Additionally, it is recommended that training courses be hold for experts and staff in organizations by specialized professors, such as experts from the space agency or university professors. The utilization of experiences of other countries, especially regions with geographical similarities (especially Sistan and Baluchistan province) can have effects on crisis management using new technologies. It is also of utmost importance to collect, organize, and analyze information about the complete history of previous crises, crisis analysis and evaluation, gained experiences, possible risk analysis, possible overcoming methods, and situations.

In case of crises that are likely to occur, the Crisis Management Headquarters should identify, evaluate, and analyze all the early signs and symptoms of crises using a variety of information systems, such as expert systems, global location systems, GIS, and communication information systems to estimate and determine the consequences and threats of crises. Identification and development of comprehensive crisis management policies, strategies, programs and plans are critical to identify, prevent, and control crises.

It is also necessary to prepare comprehensive plans based on a series of comprehensive studies and basic information in terms of scheduling, operations, and various stages of crisis management programs. Therefore, the Crisis Management Headquarters must be initially equipped with information and communications technology to have access to all required information resources. Moreover, the early signs of new crises should not be neglected; rather, they should be regarded as important warning signs to evaluate the consequences and upcoming hazards. Alarm systems are the best tools to track potential crises quickly. In this regard, programs should be planned ahead to deal with potential crises. Moreover, the organizations must have a comprehensive crisis management plan to predict and prevent the events, thereby reducing the extent of damage and loss. Additionally, the majority of damages inflicted by the crises can be reduced using expert systems and intelligent information systems, such as decision-support systems and transaction processing systems.

\section{Acknowledgments}

The authors are thankful to all those for their 
contribution to conducting this study.

\section{Conflict of Interests}

There is no conflict of interest regarding the publication of this study.

\section{References}

1. Hashemnejad F, Bidaki MS. The role of national media in crisis management and citizen relief (case study: citizens of district 22 of Tehran). Information and Communication Technology in Educational Sciences.2018; 8(2): 41-56. [In Persian].

2. Bolori M, Mokhtari N. The mental and psychological reflection of natural disasters in the literary texts of the fourth to eighth century $\mathrm{AH}$. Rich Lang Literate Studies.2018; 8(26): 17-34. [In Persian].

3. Gholipour A. Natural disaster management in the Islamic Republic of Iran and international regional cooperation. Politics Quart .2016; 3(10): 69-51. [In Persian].

4. Marto R, Papageorgiou C, Klyuev V. Building resilience to natural disasters: an application to small developing states. J Dev Econ.2018; 135: 574-86.

5. Tokakis V, Polychroniou P, Boustras G. Crisis management in public administration: The three phases model for safety incidents. Saf Sci. 2019; 113: 37-43.

6. Pennington ML, Carpenter TP, Synett SJ, Torres VA, Teague J, Morissette SB, et al. The influence of exposure to natural disasters on depression and PTSD symptoms among firefighters. California English .2018; 23(3): 102-8.

7. Ebrahimi N. Modeling of the relation of natural disasters and the economic growth using neural network. J Fundam Appl Sci. 2016; 8(2): 1677-99. [In Persian].

8. Rezaei MR, Sarai H, Bastaminia A. Investigating concepts and methods of measuring economic resilience with emphasis on natural disasters. First International Conference of Iranian Natural Hazards and Environmental Crises, Ardabili, Iran.2016; 201-17. [In Persian].

9. Traore BB, Kamsu-Foguem B, Tangara F, Tiako P. Software services for supporting remote crisis management. Sustainable Cities Soc. 2018; 39: 814-27.

10. Kamali Y, Mirzaei J. Comparative study of disaster management structure in Iran, Japan, India, and Turkey. Strategic Stud Public Policy. 2017; 7(25): 245-89. [In Persian].

11. Dave RS. Disaster management and emergency response a comparative study of managerial structures systems and processes in Gujarat India and California USA. Ahmedabad, India: Gujarat University; 2015.

12. Mehrabi N. The functional role of ICT tools in crisis management. Paramed Sci Mil Health .2014; 9(1): 48-53. [In Persian].

13. Estelaji F, Yari MH. Application of engineering techniques in crisis management (Fire department case study). Geography (Regional Planning) .2018; 8(3): 53-62. [In Persian].

14. Guembour A, Nadira R. Role of communication and technology in crisis management. Eur J Eng Formal Sci .2018; 2(2): 96-100.

15. Taghizadeh O, Latifi MF, Ardalan A. The role of advanced technologies in disasters recovery and rehabilitation. Quart Sci J Rescue Relief .2013; 5(1): 8-1. [In Persian].

16. Pérez MM, Cabrero-Canosa M, Hermida JV, García LC, Gómez DL, González GV, et al. Application of RFID technology in patient tracking and medication traceability in emergency care. $\mathbf{J}$ Med Syst.2012; 36(6): 3983-93.

17. Eghbali A, Khayati Moghaddam S, Erfanian H. Investigating the role of new technologies in the effectiveness of crisis management. 5th International Conference on Crisis Management. International Research Institute of Seismology and Earthquake Engineering, Tehran, Iran.2014. 99111. [In Persian].

18. Wojciechowicz E.H, Llewellyn CH. The role of telemedicine in disaster medicine. $\mathrm{J}$ MedSyst.2012;19(1):29-34.

19. Chung J. Conflicts and natural disaster management: a comparative study of flood control in the Republic of Korea and the United States. Disasters .2016; 40(3): 554-72.

20. Ashrafi-rizi H, Taheri B, Soleimanzadeh Najafi NS, Yarmohammadian MH. Bibliography of events and disasters. Isfahan: Isfahan University of Medical Sciences.2015. [In Persian].

21. Hataminezhad HR, Amani MM. Assessment of Tehran municipality's preparedness for disaster management with emphasis on earthquake in Tehran. Crisis Manag .2017; 9(32): 45-57. [In Persian].

22. Bourletidis K. The strategic management of market information to SMEs during economic crisis. Proc Soc Behav Sci. 2013; 73: 598-606.

23. Christos K. Foxconnian culture: an operational crisis abetted suicides. Proc Soc Behav Sci .2015; 175: 447-54.

24. Mahmoudi SM. The role of information systems in crisis management. Manag Culture .2003; 4: 59-92. [In Persian].

25. Ashrafi HR, Sharifian L, Shahgholian Ghahfarkhi M. The importance of information systems in organizations with emphasis on decision support information system (DSS) and comparison with management information system (MIS). Modern 
Res Appr Manag Account .2018, 6: 48-33. [In Persian].

26. Habibi A. Application of geographic information system (GIS) in geomorphology. Tehran: Pendar Qalam Publication. 2017. [In Persian]

27. Timmermans S. Demystifying medicine. Symb Interact .2007; 30(3): 435-9.

28. Halbich C, Vostrovsky V. GIS as spatial decision support system. Agris Online Papers Econ Inform. 2011; 3: 67-73.

29. Greenwald PW, Hsu H, Sharma R. Planning for future disasters: telemedicine as a resource. Ann Emerg Med. 2018; 71(3): 435-6.

30. Ahmadi M, Meraji M, Mashoof E. Evidence on telemedicine in Iran-systematic review. J Paramed Sci Rehabil .2018; 7(1): 112-24. [In Persian].
31. Biranvand S. Simultaneous use of GPS receivers and seismographs for use in earthquake warning systems in eastern Tehran. 7th International Conference on Comprehensive Crisis Management, Tehran, Iran.2016; 1-9. [In Persian].

32. Golabchi M. Space grid structures. Tehran: Tehran University Publication.2017. [In Persian].

33. Nisi AK, Wisse SM, Tardost $\mathrm{H}$. Investigating the effective factors on the effectiveness of emergency rescue teams for crisis response. Sci J Resc Relief. 2014; 6(2): 25. [In Persian].

34. Riahi A. Introduction to the position and application of nanotechnology and biotechnology products in the field of rescue. J Nanotechnol. 2005; 3(63): 31-40. [In Persian]. 